Journal of Architectural Research and Development

Review Article

\title{
Numerical Analysis on the Seismic Performance of Plane Irregular Structure Based on ABAQUS
}

\author{
Lina Zong*, Feng Xu, Wei Yuan, Xiaolei Ji \\ College of Civil Engineering and Architectural, Jiangsu Open University, Nanjing 210036, China
}

\begin{abstract}
Rod element and shell element were used in finite element software ABAQUS to establish dynamic elastic-plastic analysis model of the structure, the seismic performance of an irregular plane complex overrun structure numerical simulation, the structure was calculated under different input level and displacement response of the acceleration response, and analyses the force of the wear layer column and the floor of the open hole stress level. The results were compared with the shaking table test to verify the accuracy of the numerical simulation results. The results of numerical calculation were basically consistent with the experimental results, and the finite element model basically reflected the response of the structure under the simulated earthquake.

Key words: Plane Irregular structure; Elastic-plastic ; Acceleration response; Seismic performance; Weak component
\end{abstract}

Publication date: July, 2020

Publication online: 31 July, 2020

*Corresponding author: Lina Zong, zong890606@126. com

\section{Introduction}

When a large area of floor slab was missing in highrise buildings, the stress of components in the plane changed, and the mechanism of force transmission became more complex. At present, there are different methods for the modeling and analysis of the floor irregular open-hole structure, and the obtained structural analysis results will also be different. In view of the stress characteristics of the model structure, ABAQUS large-scale finite element software was used for modeling and analysis in this paper.

ABAQUS was one of the most powerful large-scale general purpose finite element analysis software, with an amazing wide range of simulation performance, had won the reputation and trust in the engineering and academic circles at home and abroad. It could not only analyze all kinds of complex linear and nonlinear solid mechanics problems, but also develop towards multiphysical field mixed simulation, and achieve systematic analysis and research, which has reached a consensus in the academic circle ${ }^{[1]}$, which has been widely used in civil engineering due to its excellent analytical ability and secondary development ability ${ }^{[2-3]}$.

This article used the finite element software test model for the dynamic elastic-plastic time history analysis under different working conditions, the model of the structure of the dynamic characteristics and seismic response of the each stage, the analysis results showed that the numerical analysis results and the shaking table test results are in good agreement, and the numerical analysis results show that the structure basically meet the fortification target structure, seismic performance was good, which verified the reliability of the shaking table test, the rationality of the design of test model. Combined with the shaking table test, the stress distribution of floor openings and the stress morphology of weak components were analyzed, the results show that the floor at the edge of the opening was more prone to stress concentration, and the seismic performance of the weak components were good, and some design suggestions were put forward for the irregular planar structure with large openings. ABAQUS could perform accurate numerical simulation on the seismic performance of irregular and complex transfinite planar structures, and provided basis for the detailed analysis of key components of the structures. 


\section{Finite element simulation model establishment of model structure}

\subsection{Selection of finite element model and analysis unit}

The finite element model was established focuses on the shaking table test model ${ }^{[4]}$ in this paper, and the dynamic elastic-plastic time history was analyzed under different working conditions. The ABAQUS finite element model diagram and typical floor structure diagram of the test structure were presented in FIG. 3 and 4 respectively. From Figure 1 and Figure 2, we could see that many floors have perforated columns, floor slabs missing, and large areas of holes, which were typical irregular planar structures.

ABAQUS software provided a variety of units, each with its own unique name (for example, when using S4R, the unit type suitable for the purpose of analysis should be selected according to the characteristics of each unit $\left.{ }^{[5]}\right)$.According to the characteristics of the model structure, beam element (B31) was selected to simulate the beam and column members in the structure, while shell element (S4R and S3R) was selected to simulate the floor slab in the structure.

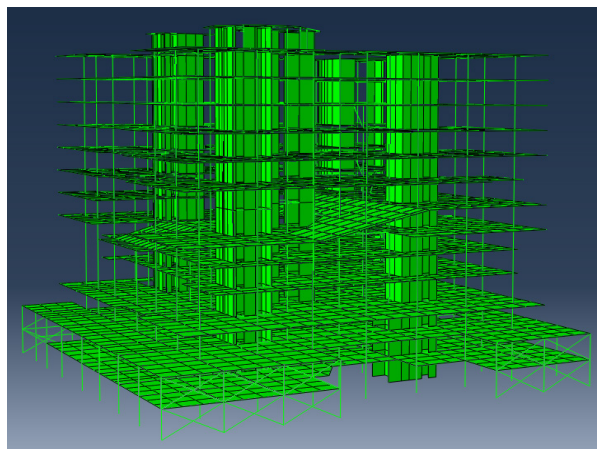

Figure 1. ABAQUS finite element model of the experimental structure

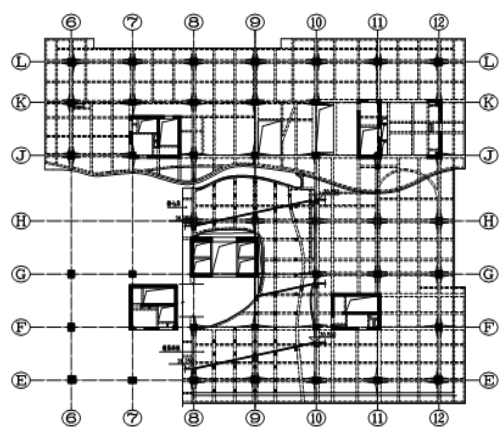

Floor plan of the seventh floor

Figure 2. Planar graphs of typical floors

\subsection{Determination of constitutive relation}

\subsubsection{Slab and wall concrete}

The plastic damage model could take into account the difference of tensile and compressive strength of concrete and the degradation and restoration of stiffness under cyclic loading. When the stress state of concrete changed from tension to compression, the crack of concrete closed and the compressive stiffness returned to the original compressive stiffness. When the stress state of concrete changed from compression to tension, the tensile stiffness of concrete could not be restored. The constitutive relation of concrete selected in this simulation was based on the Code for Design of Concrete Structures ${ }^{[6]}$ (GB50010-2010), the material strength adopts the strength standard value of the particulate concrete in the model structure, and the reinforcement information followed the reinforcement result of the model after similar design.

\subsubsection{Frame concrete}

Fiber beam elements were used in the concrete frame beam and column elements of the model structure. Based on the Timoshenko beam theory, the shear deformation stiffness could be considered, and the element stiffness could be obtained by dynamic integration twice in the section and length direction during the calculation. The concrete uniaxial hysteretic constitutive and the reinforcement uniaxial hysteretic constitutive were adopted, and the mechanical behavior was shown in Figure 3 and 4.

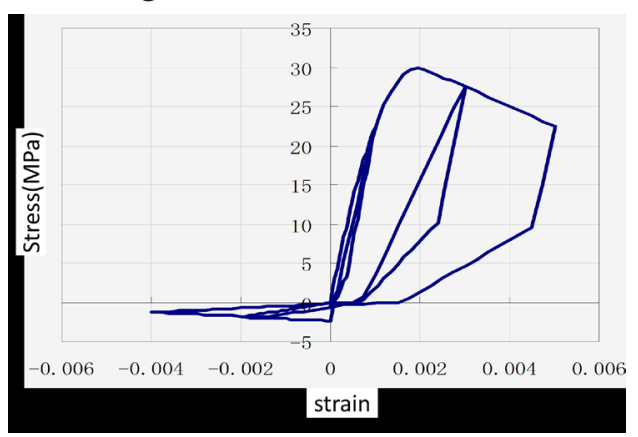

Figure 3. Constitutive model of frame concrete

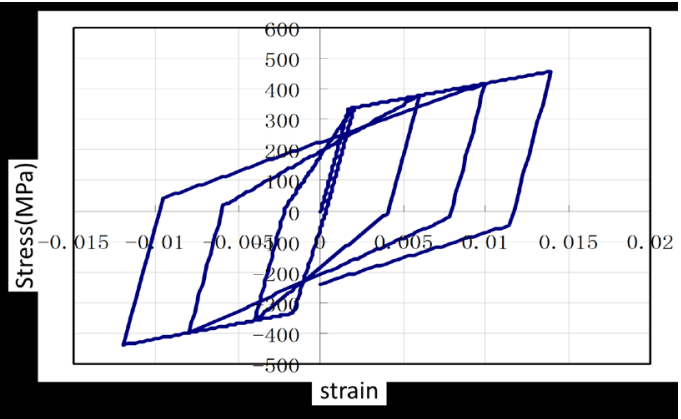

Figure 4. Constitutive model of frame rebar 


\subsubsection{Steel bone material}

Bilinear dynamic hardening model was adopted ${ }^{[7]}$, considering Bauschinger effect, no stiffness degradation occurs during the cycle. Under multi - axial stress state, adopt The Von Mises yield criteria determine whether steel yield was achieved. In the simulation process, it was assumed that the strong bending ratio of steel was 1.2 and the strain corresponding to the ultimate stress was 0.025 .

\section{Comparison of model structure test results and numerical simulation analysis results}

The numerical simulation analysis showed that each working condition corresponds to the load working condition table of the model shaking table. According to the different excitation directions, El Centro, Kobe and artificial waves were input at 7 degrees and 7 degrees $(0.15 \mathrm{~g})$ frequency-multiple $(\mathrm{F} 7, \mathrm{~F} 7(0.15 \mathrm{~g})), 7$ degrees

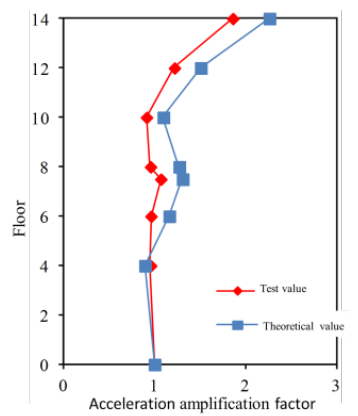

(a) Frequent earthquakes of 7 degrees

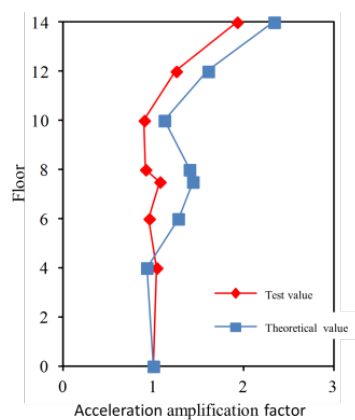

(b) Basic intensity of 7 degrees

Through the comparison of the above data, it could be seen that the natural vibration frequency errors of the three were all controlled within 5\%, and the natural vibration characteristics of the test model were in good agreement with the results of the numerical simulation.

\subsection{Comparison of acceleration of model structure}

To further compare and analyze the model structure test and finite element simulation of the earthquake response ${ }^{[8]}$. In this paper, the acceleration response of each measuring point under the corresponding working condition of the experimental model and the numerical simulation model was compared. FIG. 5 showed the comparison of the amplification coefficient of floor acceleration under the input of El Centro of the model structure with 7 degrees of frequent intensification, basic intensification, rare intensification and 8 degrees of rare intensity. In addition, the top-level acceleration response was also analyzed.

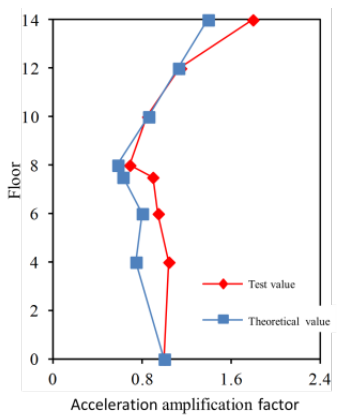

(c) Rare intensity of 7 degrees

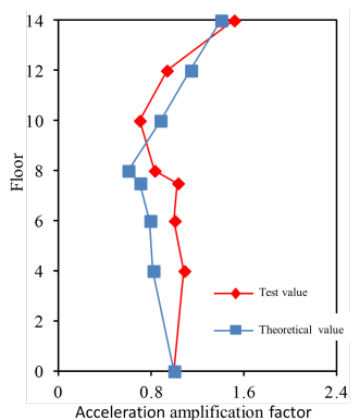

(d) Rare intensity of 8 degrees

Figure 5. Comparison of floors' acceleration amplification factor

and 7 degrees $(0.15 \mathrm{~g})$ basic intensity $(\mathrm{B} 7, \mathrm{~B} 7(0.15 \mathrm{~g}))$, 7 degrees and 7 degrees $(0.15 \mathrm{~g})$ rare intensity (S7, $\mathrm{S} 7(0.15 \mathrm{~g})), 8$ degrees Rare intensity (S8) and 8 degrees Rare intensity (S8 $(0.3 \mathrm{~g}))$, respectively.

\subsection{Comparison of natural vibration characteristics of model structure}

In this paper, the natural vibration frequency obtained by the Etabs model analysis of the prototype structure was deduced according to the experimental similarity ratio $(7.07: 1)$, and then compared with the results of model test and finite element simulation respectively. See Table 1 for details:
It could be seen from Figure 5 that the acceleration time history of the top layer of the structure was basically the same under all working conditions, and the coincidence degree was better under earthquakes with frequent intensities than that with rare intensities, and the triggering time of the peak point was consistent. Model of the tested value of flexible working stage floor acceleration amplification factor relatively numerical value was small, cause the error and model construction had a certain relationship, but distribution trend was consistent. As the floors rise, basic showed a trend of increase gradually, In particular, the 7 th $\sim 8$ th layers

Table 1. Comparative analysis on natural frequency of model structure (Hz)

\begin{tabular}{cccc}
\hline \multirow{2}{*}{$\begin{array}{c}\text { Nominal } \\
\text { modes }\end{array}$} & \multicolumn{3}{c}{ Frequency $(\mathbf{H z})$} \\
\cline { 2 - 4 } $\mathbf{1}$ & Etabs prototype similarity conversion value & Shaking table test value & ABAQUS finite element model value \\
\hline $\mathbf{2}$ & 5.529 & 5.610 & 5.650 \\
$\mathbf{3}$ & 5.796 & 5.972 & 6.098 \\
\hline
\end{tabular}


are equipped with inclined plates, which improves the lateral stiffness between the floors and increases the acceleration amplification to a certain extent. Under rare intensity input, as a result of the test and numerical calculation of the occurrence and damage of difference, caused the top time history curve of alignment was lower than that in frequent intensity input. However, from the distribution of floor acceleration amplification coefficient, the experimental and numerical values are basically consistent, the distribution curves are in good agreement, and the attenuation of acceleration amplification effect caused by damage development of the model is reflected in the same way. From the comparative analysis of acceleration, it could be seen that the acceleration response law obtained by test and numerical calculation was basically consistent. The finite element model basically reflected the response of the structure under the simulated earthquake, and at the same time, the reliability of the shaking table test results was preliminarily verified.

\subsection{Displacement comparison of the model structural}

In order to further compare and analyze the seismic response between model structural test and finite element simulation ${ }^{[9]}$. In this paper, the displacement response of each measuring point under the corresponding working condition of the experimental model and the numerical simulation model was compared. Figure 6-8 showed the relative displacement envelope comparison of the central measuring point under the condition of 7 degrees of frequent intensification, basic intensification and rare intensification. The comparison of top displacement response under corresponding operating conditions was also analyzed.

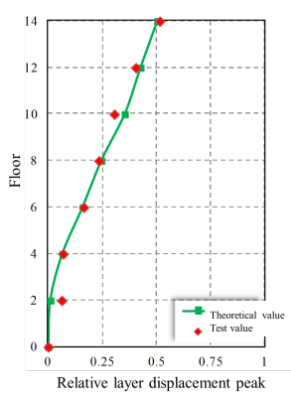

(a) El Centro wave

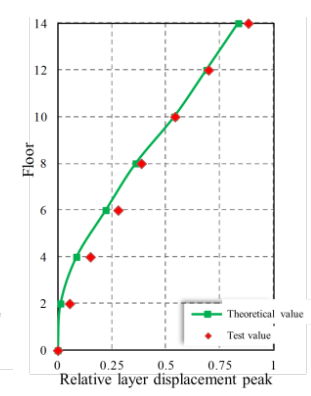

(b) Kobe wave

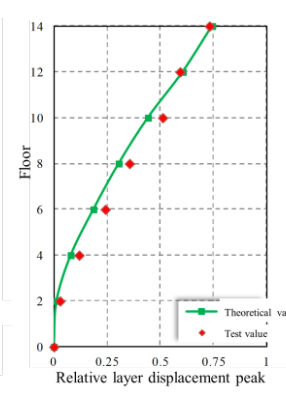

(c) Artificial wave
Figure 6. Comparison of displacement response of the model's floors under frequent earthquake intensity 7

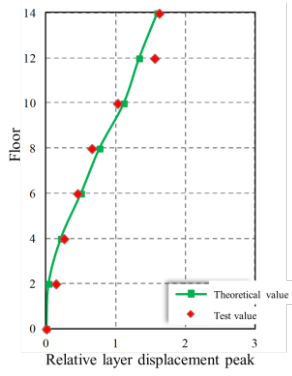

(a) El Centro wave

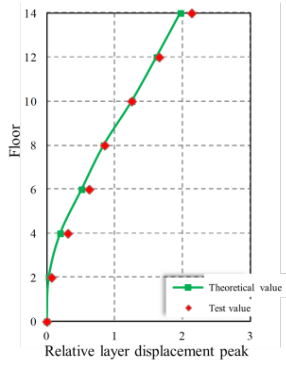

(b) Kobe wave

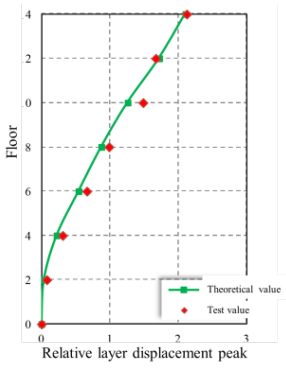

(d) Artificial wave
Figure 7. Comparison of displacement response of the model's floors under basic earthquake intensity 7

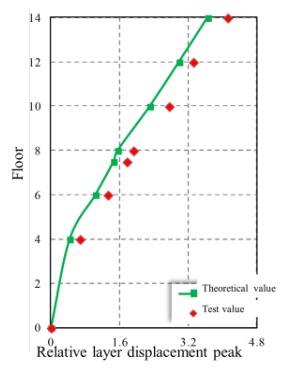

(a) El Centro wave

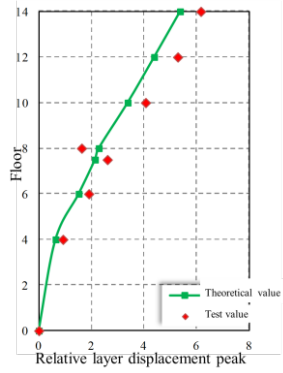

(b) Kobe wave

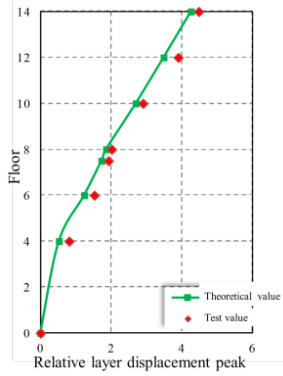

(c) Artificial wave
Figure 8. Comparison of displacement response of the model's floors under seldom earthquake intensity 7

As could be seen from the figure above, the relative displacement response of the model test under frequent intensity earthquakes was in good agreement with the results of finite element calculation and analysis, the time point triggered by the displacement peak was basically the same, and the relative lateral displacement distribution curve of each floor was basically consistent, showing good similarity in shape and trend. When input the rarely earthquake intensity, increase between experimental results and numerical calculation error, which is related to the model casting and the postprocessing of the test. Due to the displacement response was based on the acquisition of acceleration time history signal after filtering and integrating to get, the size of the filter and chopping frequency selection would affect the result of displacement. From the comparison of relative displacement peaks, the numerical calculation results of the three seismic waves were smaller than the test results, but the distribution rules are consistent and increase with the rise of the floors. On the whole, the measured displacement response trend of the model was basically consistent with that of the model calculated by numerical method, and the finite element model could reasonably simulate the displacement response of the model structure under the action of earthquake.4 Stress analysis of perforated column

Due to the lack of floor slab on the fifth to sixth story 
side trusses of the structure, the trusses on the sixth to twelfth axis and the $\mathrm{E}$ to $\mathrm{L}$ axis side trusses of the structure formed a cross-layer column, and the local position made the long and short columns common. In order to further obtain the stress state under the seismic action of the wear layer column, the following typical wear layer column was respectively taken for the stress analysis, and the stress on the frame column corresponding to the adjacent layer was also taken make a comparison. Figure 9 showed the layout diagram of the wear layer columns (A, B, C, D and E).

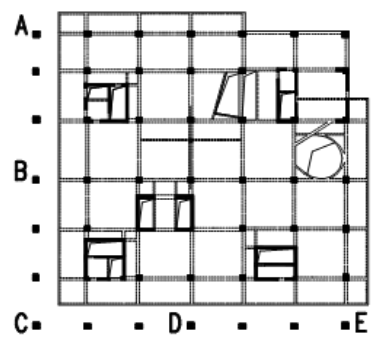

Fig.9 Layout diagram of wear layer columns

Finite element software was used to input the ground motion in $\mathrm{Y}$ direction of the model structure, and the stress state of the model structure was obtained. Then the stress state of the layered columns of the prototype structure under corresponding intensity could be obtained through the dynamic similarity relationship. Table 2 showed the calculated values of the internal forces of the frame columns at the corresponding positions of each layered column and adjacent layers respectively. As can be seen from the table:
(1) Under the action of earthquake, the section torque of the corner wear layer column (column A, Column $\mathrm{C}$ and column E) was larger than that of the middle column (column B and D), indicating that the torsion effect of the corner was more obvious. Contrast column A, C, E, found that the torsional response of wearing layer column $\mathrm{C}$ was larger than that of the other two. Investigated its reason: compared with the column $\mathrm{A}$ and column $\mathrm{E}$, column $\mathrm{C}$ location floor in two directions are missing, caused the floor to the vertical component of original contribution to the stiffness in two directions was abate, made the vertical component of the torsional response of the further amplification.

(2) It could be seen that the shear force in $Y$ direction was larger than that in $\mathrm{X}$ direction for the other wear layer columns, and the difference of shear force in column $\mathrm{C}$ was very small, even the shear force in $\mathrm{X}$ direction was larger than that in $\mathrm{Y}$ direction. It indicated that the shearing force unloading effect of corner wear layer column $\mathrm{C}$ was obvious, which further indicated that it was more sensitive to the response of torsion.

(3) By comparing the stress of the frame column at the corresponding position of the adjacent layer, it was not difficult to find that the seismic shear force on the column passing through the layer was smaller than that on the frame column of the adjacent layer, and the maximum difference between the two was nearly 10 times. The main reason was that there was no lack of adjacent floor slab, and the contribution of floor slab to

Table 2. Internal force values of skip-floor columns in $\mathrm{Y}$ direction

\begin{tabular}{|c|c|c|c|c|c|c|}
\hline \multirow{2}{*}{ The column number } & \multirow{2}{*}{ location } & \multicolumn{2}{|c|}{ Shear $(\mathrm{kN})$} & \multicolumn{2}{|c|}{ Bending moment $(\mathrm{kN} \cdot \mathrm{m})$} & \multirow{2}{*}{$\begin{array}{c}\text { Torque }(\mathrm{kN} \cdot \mathrm{m}) \\
T\end{array}$} \\
\hline & & $V x$ & Vy & $M x$ & My & \\
\hline Upper corresponding column & & 83.70 & 327.54 & 811.69 & 201.63 & 34.82 \\
\hline \multirow[t]{2}{*}{ Wear layer column A } & top & 11.91 & 72.27 & 325.02 & 80.18 & 31.74 \\
\hline & bottom & 12.63 & 69.84 & 499.13 & 64.96 & 31.74 \\
\hline Lower corresponding column & & 118.08 & 392.01 & 1349.64 & 379.51 & 30.86 \\
\hline Upper corresponding column & & - & - & - & - & - \\
\hline Wear layer column B & bottom & 34.74 & 273.66 & 1296.76 & 161.01 & 27.13 \\
\hline Lower corresponding column & & 52.35 & 237.12 & 799.70 & 188.35 & 13.45 \\
\hline Upper corresponding column & & 46.56 & 237.54 & 716.71 & 149.03 & 16.37 \\
\hline \multirow[t]{2}{*}{ Wear layer column C } & top & 48.78 & 43.68 & 188.64 & 292.40 & 46.86 \\
\hline & bottom & 50.40 & 41.25 & 329.16 & 284.69 & 46.86 \\
\hline Lower corresponding column & & 196.83 & 408.45 & 1376.13 & 712.47 & 35.07 \\
\hline \multirow[t]{2}{*}{ Wear layer column D } & top & 48.75 & 98.79 & 579.95 & 292.70 & 32.58 \\
\hline & bottom & 50.16 & 97.38 & 686.88 & 354.14 & 32.58 \\
\hline Lower corresponding column & & 137.64 & 139.62 & 537.59 & 368.63 & 11.85 \\
\hline Upper corresponding column & & 121.74 & 449.76 & 1184.74 & 235.67 & 30.71 \\
\hline \multirow[t]{2}{*}{ Wear layer column E } & top & 25.62 & 63.72 & 308.18 & 153.39 & 32.52 \\
\hline & bottom & 27.06 & 62.70 & 441.17 & 153.77 & 32.52 \\
\hline Lower corresponding column & & 206.01 & 483.42 & 1627.75 & 689.47 & 43.14 \\
\hline
\end{tabular}


the stiffness of vertical components was not reduced, the horizontal seismic force was well transmitted to the frame column through the floor slab and the frame beam, while the absence of the floor slab on the fifth to sixth stories weaken the connection between the floor slab and the side column, making the calculated length of the original frame column lengthen, the slenderness ratio increased, the shear stiffness of the column decreased, and the seismic shear force assigned to the column under the action of earthquake also decreased accordingly.

(4) Contrast analysis of wear layer column C and its frame column of adjacent layers, it could be seen that: although the seismic shear force of the corresponding frame columns of the adjacent layer was greater

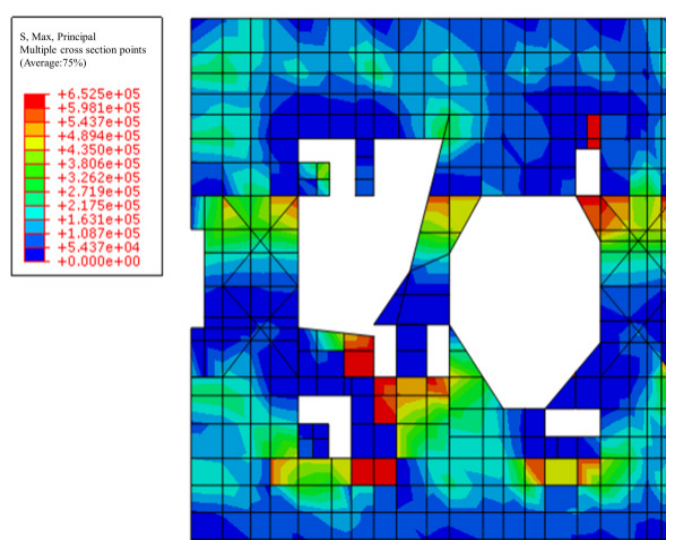

(a)Principal compressive stress distribution
Mpa, had more than concrete tensile stress limit value, that the floor slab crack, material into the nonlinear state.

During the test, it was observed that the development of cracks was mainly concentrated at the connection between the floor slab at the edge of the hole and the vertical component. FIG. 11 showed the comparison diagram of the tensile crack position of typical floor slab subjected to experimental analysis and numerical calculation. Due to the influence of various factors in the process, the observation of cracks was not very comprehensive. But on the whole, the numerical simulation results reflect the weakness and failure of the floor slab.

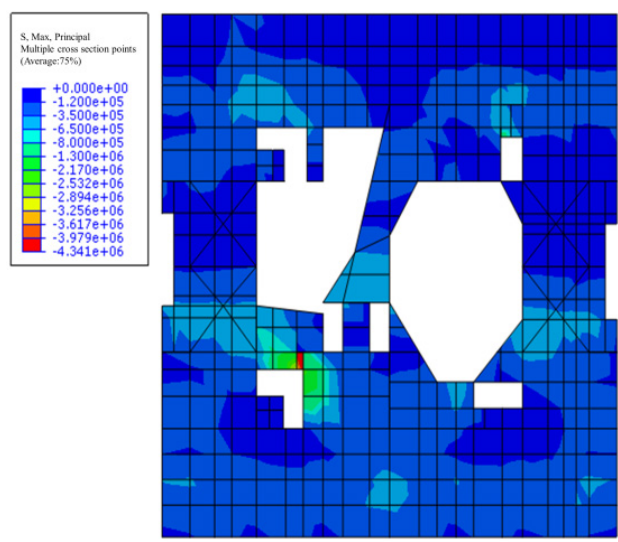

(b)Principal tensile stress distribution

Figure 10. Diagram of floor stress distribution

than that of wear layer column. The shear force in Y direction undertaken by the adjacent lower column was nearly 10 times that of the column passing through, but its torque was all smaller than that of the wear layer column, indicating that the lack of floor slab had a great influence on the torsion resistance of the wear layer column, which further indicated that the contribution of floor slab to the torsion stiffness of components could not be ignored.

\section{Stress analysis of floor slab}

FIG. 10 showed the distribution of tensile and compressive stress on the 13-story floor of the structure under the input of rare earthquakes. It could be seen from the diagram: nest end floor and floor open hole edge and the vertical component of the connection parts of stress concentration phenomenon was obvious, are more likely to form weak positions, the maximum principal compressive stress in the figure was 0.653 $\mathrm{Mpa}$, the maximum principal tensile stress was 4.341

\section{Stress analysis of split-Layer inclined plate}

The structure was equipped with staggered inclined plate between the 7th and 8th layers, and the force under earthquake action was more complex ${ }^{[10-11]}$, FIG. 11 showed the plate tensile and compressive stress distribution under the input of rare earthquakes.

It could be seen that the stress concentration at the bottom of the inclined plate was more obvious than that at the top, and the maximum tensile and compressive stress occurs at the bottom corner of the plate. The maximum compressive stress reached $0.649 \mathrm{mpa}$ and the maximum tensile stress reached $2.419 \mathrm{mpa}$, exceeding the ultimate tensile stress of concrete. During the test, through the analysis of the strain data at the bottom of the inclined plate, it was found that the strain at the bottom of the inclined plate was larger than that at the top, and the tensile strain at the corner had exceeded the cracking strain of concrete, which was basically consistent with the results of the finite element simulation. 


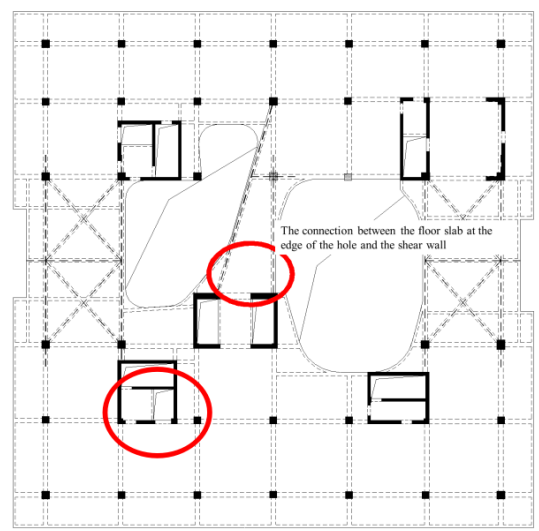

(a) Fracture distribution in test

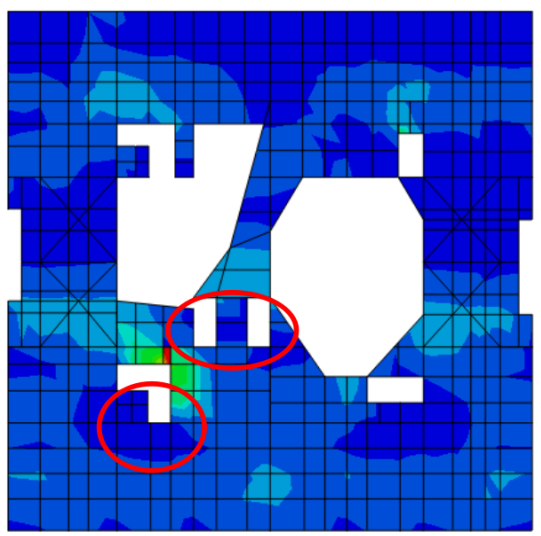

(b) Numerical analysis of tensile stress distribution

Figure 11. Comparison of cracks develop and distribution of typical floor

\section{Conclusions and Recommendations}

\subsection{Conclusion}

By comparing the model of the structure of the numerical analysis results and the shaking table test results, found that the natural frequency, floor acceleration and displacement time history curves of the model structure analyzed by the two methods were in good agreement, the finite element model structure of the numerical simulation model was established and the analysis method and the results had a certain credibility, and according to the proposed model simplified design method of design of the model was reasonable and test data was reliable.

The numerical analysis results of the model structure showed that the displacement Angle between the layers of the model meets the requirements of the seismic code, and the maximum inter-layer displacement Angle under low intensity occur at the 9th to 10th layer. When the loading intensity increases, the position of the maximum inter-layer displacement Angle gradually moved up, which was basically consistent with the test results. The average floor displacement ratio of individual seismic waves in elastic earthquakes exceeds the 1.2 limit specified in the code, which indicated that there was a low degree of torsion irregularity in the model structure, which was basically consistent with the experimental analysis results.

In the process of numerical simulation, the seismic shear forces on the wear layer column in the 4 th to 7 th floors were smaller than those on the corresponding frame columns in the adjacent floors, but the torsion response of the components was more obvious, and the torsion response of the wear layer column in the corner was more sensitive, indicating that the lack of floor weakens the torsional stiffness of the vertical components. Stress concentration was easy to occur on the floor at the edge of the entrance, and the connection between the vertical component and the floor was more obvious. In the process of seismic input, the Angle was more prone to stress concentration, which was mainly caused by tensile failure. The numerical analysis showed that the Angle has cracked, which is generally consistent with the experimental results. In general, the seismic performance of the structure was good, and the ductility and energy dissipation were better.

\subsection{Advice}

The absence of floor slab resulted in the sharing of length columns in local floors. The slenderness ratio of the wear layer column was relatively larger and the shear stiffness was small, which was distributed under the action of earthquake the horizontal shear force was smaller, but its torsion effect could not be ignored. Especially, the corner wear layer column was more sensitive to the torsion response. It was suggested to enhance the torsion resistance of the whole floor by strengthening the strength of the column itself or improving the connection stiffness between the wear layer columns.

In this structure, as a component connecting two floors, the split-layer inclined plate was subjected to a large horizontal seismic force under the action of earthquake, and the bottom was subjected to a large force. It was suggested to add radioactive reinforcement at the bottom corner to improve its shear bearing capacity.

\section{References}

[1] Zhu R. Study on the Seismic performance analysis of irregular planar structures with floor holes [D]. Anhui Jianzhu 
University, 2018.

[2] Huang XN, Wang W, Wang N, et al. Study on torsion resistance design of planar irregular base-isolated structures $[\mathrm{J} / \mathrm{OL}]$. Journal of Seismic Engineering :1-7.

[3] Du YF, Zhang WL, Huang XN. Damping design of planar irregular RC frame structure based on force transmission path [J]. Journal of seismic engineering,2017, 39(3): 404-410+424.

[4] Wang B, Wang SG, Liu WQ, et al. Experimental study on vibration table of plane Irregular complex Over-limit Structure[J]. Journal of Vibration and Impact, 2014, 33(16): 135-141

[5] Xu L, Hu H. Spatial structure optimization of buildings with Seismic constraints[J]. Journal of Seismic Engineering, 2008, 40(6): 1231-1235+1242.

[6] Code for Design of Concrete Structures [S][D]. 2010.

[7] Yu Y. Static elastic-plastic seismic performance analysis of a 1-shaped high-rise frame-shear wall structure [J]. Urban housing,2019,26(07):121-123.

[8] Lv XL, Zhou Y, Lu WS. Shaking Table Test and Numerical Analysis of A Complex High-rise Building[J]. The Structure Design of Tall and Special Buildings, 2007, 16(2): 131-164.

[9] Feng CC, Zhu NH, He XL. Influence of buckling restrained support on seismic strengthening performance of building structures[J]. Journal of geoengineering engineering, 2019, 41(2): 353-359.

[10] Du WT. Seismic performance analysis of H-beam frame Structure under different supports[D]. Anhui Jian zhu University,2018.

[11] Yuan HZ, Xu H. Study on the gravity load capacity of building top floor under horizontal earthquake[J]. Chinese journal of seismic engineering, 2019, 41(3): 613-618. 